\title{
Do angiotensin converting enzyme inhibitors represent a progress in hypertension care in diabetes mellitus?
}

\author{
P.T. Sawicki, I. Mühlhauser, T. Baba and M.Berger \\ Department of Nutrition and Metabolism, WHO-Collaborating Centre for Diabetes, Heinrich-Heine University of Düsseldorf, FRG
}

Introduction. The excess mortality of Type 1 (insulindependent) diabetes mellitus is mainly due to the development of diabetic nephropathy with proteinuria and hypertension as its leading clinical features. Only quite recently, it has been recognized that the prognosis of diabetic nephropathy, including its mortality, depends largely on the degree of hypertension control $[1,2]$. In Type 2 (non-insulin-dependent) diabetes mellitus, excess mortality is due to cardiovascular disease and hypertension plays a leading role as a risk factor in this context [3]. Although, specific intervention studies on hypertension in Type 2 diabetes are not available, treatment of hypertension is strongly recommended in both types of diabetes [4]. Apart from these facts [1-4], the obvious current vogue of interest in hypertension in diabetic patients has been triggered by the introduction and marketing of new antihypertensive agents, such as angiotensin converting enzyme inhibitors. Actually, it has been postulated that these new antihypertensive drugs represent a major progress in the hypertension care of diabetic patients. In the following, we challenge this view by analysing the evidence for suggested advantages of the new drugs over conventional antihypertensive agents, such as thiazide diuretics and $\beta$-blockers.

\section{Do angiotensin converting enzyme inhibitors exert a specific nephroprotection?}

In Type 1 (insulin-dependent) diabetes, preservation of glomerular function due to lowering of intraglomerular pressure independent of the systemic blood pressure

\footnotetext{
The section "For debate..." is open to contributions dealing with issues of a particularly debatable nature in diabetology. Contributions are published either standing by themselves or accompanied by invited comments. Other comments from the readership may be published as Letters to the Editor. Manuscripts intended for publication in this section of the journal are accepted at the discretion of the Editor-in-Chief and may be subject to a referee procedure.
}

lowering effect has been suggested as a specific action of angiotensin converting enzyme inhibitors (ACEIs) [5]. However, this hypothesis still remains controversial in animal studies [6-8] and its relevance for human diabetic patients is uncertain $[9,10]$. Several studies on the effects of ACEIs in Type 1 diabetic patients have claimed to address this issue. In order to document a specific nephroprotection by ACEIs in patients with diabetic nephropathy, an improvement of prognosis, i.e. a retardation of the loss of renal function, over and above the effect of the reduction of systemic blood pressure, by the drug needs to be proven. This would require a randomized prospective study in patients with diabetic nephropathy comparing the effects of ACEIs and other antihypertensive agents on the course of renal function; under both models of treatment comparable degrees of blood pressure control would have to be maintained throughout the study. To date, no such study has been performed. In contrast, various reports available in the literature are based upon uncontrolled studies, with conflicting results $[11,12]$.

In one retrospective analysis [13], captopril treatment turned out to be equally or, if anything, less effective in retarding the decline of glomerular filtration rate: $5.8 \mathrm{ml} \cdot \mathrm{min}^{-1} \cdot$ year $^{-1}$ on captopril vs $4.7 \mathrm{ml} \cdot \mathrm{min}^{-1} \cdot$ year $^{-1}$ on conventional treatment. Furthermore, it has been claimed that ACEIs may even be beneficial in normotensive diabetic patients by reducing albuminuria $[14,15]$. However, these studies have also included patients with blood pressure readings above $140 / 90 \mathrm{~mm} \mathrm{Hg}$ - values which are not normotensive according to definitions of the World Health Organisation and International Society of Hypertension [16]. It is of note that a similar beneficial effect on albuminuria in "normotensive" Type 1 diabetic patients has been reported for the $\beta$-blocker metoprolol [17]. Thus, to date observed beneficial effects on renal function cannot be attributed to a specific nephroprotective effect of ACEIs, but are rather due to the reduction of systemic blood pressure as such. 


\section{Do ACEIs improve glucose tolerance?}

It has been suggested that ACEIs may improve insulin sensitivity and, hence, glucose tolerance by yet unknown mechanisms [18]. To substantiate such a hypothesis, adequate long-term evaluations of glucose metabolism during ACEI therapy have to be awaited. Since blood pressure lowering by other means [19] may be associated with increasing insulin sensitivity, such studies would have to be carried out including appropriate control groups. In the meantime, available evidence in Type 1 and Type 2 diabetic patients treated with ACEIs does not indicate any clinically significant change in glucose metabolism attributable to the ACEI medication $[14,15$, 20].

\section{Do ACEIs have fewer side effects than conventional antihypertensive drugs?}

It has been suggested that ACEI therapy is associated with a better quality of life due to a reduced incidence of side effects when compared to conventional antihypertensive agents. Much of this suggestion stems from a prospective controlled trial in non-diabetic hypertensive men comparing captopril, methyldopa and propranolol [21]. However, methyldopa and propranolol are not recommended as first line drugs in diabetic patients [4]. Later studies in non-diabetic patients showed that the overall frequency of side effects of ACEIs was not significantly different when compared to the cardioselective $\beta$-blocker atenolol [22] or a combination of triamterene and hydrochlorothiazide [23].

As a further potential advantage of the new drugs it is assumed that ACEIs do not mask or prolong insulin-induced hypoglycaemia in Type 1 diabetic patients as (noncardioselective) $\beta$-blocking agents might do [4]. But the risk of this potentially hazardous side effect can be kept at a minimum by using cardioselective $\beta$-blockers in low doses $[24,25]$. Even at low levels of glycosylated haemoglobin, the incidence of severe hypoglycaemia does not appear to be increased under such therapy in our experience [26]. On the other hand, two astonishing cases of severe hypoglycaemia briefly after initiation of captopril therapy in chronically hyperglycaemic Type 2 diabetic patients on sulfonylurea plus biguanide medication have been reported [27].

In essential hypertension and in Type 2 diabetic patients, treatment with diuretics has been associated with a potassium-loss mediated impairment of glycaemic control $[28,29]$. However, this problem can be minimized by a low-dose thiazide diuretic treatment in combination with a potassium sparing diuretic $[28,30]$. The results of a recently published study comparing the influence of diuretics and ACEIs on glucose metabolism can not be attributed to a drug specific effect, since potassium balance - a major confounding factor in studies on insulin sensitivity - was not maintained in this study [29]. The use of cardioselective $\beta$-blockers has not led to a significant deterioration of glycaemic control in Type 2 diabetic patients [31]. Two recent publications have claimed adverse effects of $\beta$-blocker therapy on glucose metabolism $[32,33]$. However, the validity of both studies is questionable [34], since neither included appropriate control groups, rendering any causal relationship between antihypertensive treatment and impaired glucose tolerance highly speculative. Rather, the results of the studies were due to weight gain [32] and the particular genetic background [33] in the patients receiving $\beta$-blockers.

It has been suggested that ACEI treatment is superior to conventional antihypertensive agents with respect to changes in serum lipid profiles. Adverse effects of conventional antihypertensive agents on lipid metabolism have been repeatedly described; these effects may be transient, however. In fact, in non-diabetic hypertensive patients long-term therapy with thiazide diuretics or cardioselective $\beta$-blockers does not increase serum cholesterol concentrations in most of the trials [35-37]. No long-term studies are available for diabetic patients and no such studies exist for ACEIs.

On the other hand, severe and life-threatening side effects have been reported for ACEI therapy, such as severe hypotension, hyperkaliaemia, deterioration of renal function, neutropoenia, angio-oedema and urticaria. In addition, a rather large number of less serious and reversible side effects associated with ACEI treatment have been communicated, such as cough, rash and taste disturbance. Women of childbearing age must not take ACEIs unless they use effective contraception [38].

Finally, it should be remembered that conventional antihypertensive therapy may have desirable side effects, which could be of special relevance for diabetic patients. Thus, diuretics can lower excessive body sodium, which has been related to the pathophysiology of hypertension in diabetes [39], and long-term thiazide use may protect against osteoporosis and hip fractures in the elderly [40]. Betablockers are effective drugs in the primary and secondary prevention of coronary heart disease [37]. In this context it is of note, that the only documentation of an improvement of the prognosis of diabetic nephropathy and the mortality of these patients is based upon blood pressure lowering therapy with conventional antihypertensive agents [2].

A particular note is warranted concerning the antihypertensive therapy in Type 2 diabetic patients, the majority of whom are in the geriatric age range and have already developed atherosclerotic disease [3]. Special caution is warranted concerning ACEI treatment in Type 2 diabetic patients with renal insufficiency [41], severe chronic heart failure [42] advanced atherosclerosis [43], and specifically with renal artery stenosis - a frequent finding in hypertensive Type 2 diabetic patients [44]. In elderly multimorbid Type 2 diabetic patients, the potential benefit of antihypertensive drug treatment must be carefully balanced against the increasing risk of pharmacological therapy.

In summary, unless documented by adequate prospective and controlled trials the suggested decreased incidence of side effects and the improved quality of life during ACEI therapy compared to the treatment with conventional antihypertensive agents in diabetic patients must remain hypothetical. 


\section{Conclusions}

Obviously, the introduction of new antihypertensive drugs, as promising they may ever be, will by itself not lead to an improvement of the overall quality of hypertension care in diabetic patients. Rather, the standards of hypertension care in unselected patient populations will depend (on the part of physicians) on systematic attempts to diagnose early and to initiate effective therapy, and (on the part of patients) on adherance to agreed therapeutic procedures [26].

In contrast to the tremendous interest in new pharmaceutical principles in antihypertensive therapy, surprisingly few attempts have been directed towards assessment and improvement of overall quality of hypertension care in diabetic patients. The few available data indicate very infrequent blood pressure measurements in diabetic patients both in general practitioners' offices and in diabetes centres $[45,46]$, and high percentages of patients with either untreated hypertension [47] or insufficient blood pressure control despite treatment $[26,46]$.

These problems are most unlikely to be solved by the mere introduction of ACEIs or any other new antihypertensive drug. One may even fear that the emphasis on promoting such new, still incompletely evaluated drugs may detract physicians and patients from the necessity to comply to tedious rules of long-term hypertension care using well established therapeutic principles. On the other hand, one might hope that the present most active marketing campaign for $\mathrm{ACEIs}$ will foster the interest for the real problems of hypertension care in diabetes. In this indirect way, the ACEIs may indeed contribute to the urgently needed improvement of hypertension care in diabetic patients.

\section{References}

1. Mogensen CE (1982) Long term antihypertensive treatment inhibiting progression of diabetic nephropathy. $\mathrm{Br}$ Med $\mathbf{J} 285$ : 685688

2. Parving HH, Hommel E (1989) Prognosis in diabetic nephropathy. Br Med J 299:230-233

3. Panzram G (1987) Mortality and survival in Type 2 (non-insulindependent) diabetes mellitus. Diabetologia 30: 123-131

4. The Working Group on Hypertension in Diabetes (1987) Statement on hypertension in diabetes. Final Report. Arch Intern Med 147:830-842

5. Zatz R, Dunn BR, Meyer TW, Anderson S, Rennke HG, Brenner BM (1986) Prevention of diabetic glomerulopathy by pharmacological ameloration of glomerular capillary hypertension. $\mathrm{J}$ Clin Invest 77: 1925-1930

6. Bank N, Klose R, Aynedjian HS, Nguyen D, Sablay LB (1987) Evidence against increased glomerular pressure initiating diabetic nephropathy. Kidney Int 31: 898-905

7. Yoshioka T, Shiraga H, Yoshida Y, Fogo A, Glick AD, Deen WM, Hoyer JR, Ichikawa I (1988) "Intact Nephrons" as the primary origin of proteinuria in chronic renal disease. J Clin Invest 82: 1614-1623

8. Baba T, Sawicki PT (1989) Enalapril retards glomerular basement membrane thickening and albuminuria in the diabetic rat: are these effects specific for enalapril? Diabetologia 32:829 (letter)

9. Drummond K, Levy-Marchal C, Laborde K, Kindermans C, Wright C, Dechaux M, Czernichow P (1989) Enalapril does not alter renal function in normotensive, normoalbuminuric, hyperfiltering Type 1 (insulin-dependent) diabetic children. Diabetologia 32: 255-260

10. Baba T, Murabayashi S, Takabe K (1989) Comparison of the renal effects of angiotensin converting enzyme inhibitor and calcium antagonist in hypertensive Type 2 (non-insulin-dependent) diabetic patients with microalbuminuria: a randomised controlled trial. Diabetologia 32: 40-44

11. Taguma Y, Kitamoto Y, Futaki G, Ueda H, Monma H, Ishizaki M, Takahashi H, Sekino H, Sasaki Y (1985) Effect of captopril on heavy proteinuria in azotemic diabetics. N Engl $\mathbf{J}$ Med 313: $1617-1620$

12. Hay U, Ludvik B, Gisinger Ch, Schernthaner G (1988) Fehlender Effekt der ACE-Inhibition auf die Makroproteinurie bei diabetischer Nephropathie - eine Langzeitstudie über 6 Monate. Schw Med Wochenschr 118: 165-169

13. Parving HH, Hommel E, Smidt UM (1988) Protection of kidney function and decrease in albuminuria by captopril in insulin dependent diabetics with nephropathy. Br Med J 297: 1086-1091

14. Marre M, Leblanc H, Suarez L, Guyenne TT, Menard J, Passa P (1987) Converting enzyme inhibition and kidney function in normotensive diabetic patients with persistent microalbuminuria. Br Med J 294: 1448-1452

15. Parving HH, Hommel E, Nielsen MD, Giese J (1988) Effect of captopril on blood pressure and kidney function in normotensive insulin dependent diabetics with nephropathy. Br Med J 299: $533-536$

16. World Health Organisation (1986) Guidelines for treatment of mild hypertension: memorandum from a WHO/ISH meeting. Bulletin of WHO 64:31-35

17. Friedmann PJ, Dunn PJ, Jury DR (1986) Metoprolol and albumin excretion in diabetes. Lancet II: 1042-1043 (letter)

18. Rett K, Wicklmayr M, Tschollar G, Dietze G, Mehnert H (1988) Role of angiotensin-converting enzyme inhibitors in early antihypertensive treatment in non-insulin dependent diabetes mellitus. Postgrad Med J 64 [Suppl 3]: 69-73

19. Pollare T, Lithell H, Selinus I, Berne C (1988) Application of prazosin is associated with an increase of insulin sensitivity in obese patients with hypertension. Diabetologia 31: 415-420

20. Moore MP, Elliott TW, Nicholls MG (1988) Hormonal and metabolic effects of enalapril treatment in hypertensive subjects with NIDDM. Diabetes Care 11: 397-401

21. Croog SH, Levine S, Terta MA, et al. (1986) The effects of antihypertensive therapy on the quality of life. N Engl J Med 34: 1657-1664

22. Edmonds D, Greminger P, Locher R, Knorr M, Vetter H, Vetter W (1986) Enalapril as a first-step agent in essential hypertension: a comparative study with atenolol. J Hypertension 4 [Suppl 5]: 406-409

23. Woo J, Woo KS, Kin T, Vallance-Owen J (1987) A single-blind, randomized, cross-over study of angiotensin-converting enzyme inhibitor and triamterene and hydrochlorothiazide in the treatment of mild to moderate hypertension in the elderly. Arch Intern Med 147: 1386-1389

24. Clausen-Sjöborm N, Lins PE, Adamson U, Curstedt T, Hamberger B (1987) Effects of metoprolol on the counter-regulation and recognition of prolonged hypoglycemia in insulin-dependent diabetics. Acta Med Scand 222: 57-63

25. Blohme G, Lager I, Lönnroth P, Smith U (1981) Hypoglycaemic symptoms in insulin-dependent diabetics. A prospective study on the influence of beta-blockade. Diabete and Metab 7:235-238

26. Mühlhauser I, Sawicki P, Didjurgeit U, Jörgens V, Berger M (1988) Uncontrolled hypertension in IDDM Assessment of patients' desires about hypertension treatment and improvement of blood pressure control by a structured hypertension treatment and teaching programme. Diab Med 5: 693-698

27. Rett K, Wicklmayr M, Dietze GJ (1988) Hypoglycaemia in hypertensive diabetic patients treated with sulfonylureas, biguanides and captopril. N Engl J Med 24: 1609 (letter)

28. Amery A, Berthaux P, Bulpitt C, Deruyttere M, Schaepdryver A, Dollery C, Fagard R, Forette F, Hellemans J, Lund- 
Johansen P, Mutsers A. Tuomilehto J (1978) Glucose interolance during diuretic therapy. Results of trial by the European working party on hypertension in the elderly. Lancet I: 681-683

29. Pollare T, Lithell H, Berne C (1989) A comparison of the effects of hydrochlorothiazide and captopril on glucose and lipid metabolism in patients with hypertension. N Engl J Med 321: 868-873

30. Vardan S, Mehrotra KG, Mookherjee S, Willsey GA, Gens JD, Green DE (1987) Efficacy and reduced metabolic side effects of $15 \mathrm{mg}$ chlorthalidone formulation in the treatment of mild hypertension. JAMA 258: 484-488

31. Wright AD, Barber SG, Kendall MJ, Poole PH (1979) Betaadrenoceptor-blocking drugs and blood sugar control in diabetes mellitus. Br Med J I: 159-161

32. Pollare T, Lithell H, Selinus I, Berne C (1989) Sensitivity to insulin during treatment with atenolol and metoprolol: a randomised, double blind study of effects on carbohydrate and lipoprotein metabolism in hypertensive patients. Br Med J 298: $1152-1157$

33. Skarfors ET, Lithell HO, Selinus I, Aberg H (1989) Do antihypertensive drugs precipitate diabetes in predisposed men? $\mathrm{Br}$ Med J 298: 1147-1152

34. Bains W (1989) Antihypertensive drugs and diabetes in predisposed men. Br Med J 298: 1643 (letter)

35. Burris JF, Freis ED (1985) Thiazids do not cause long-term increases in serum lipid concentrations. Arch Intern Med 145: 2264-2265

36. Moser M (1988) In defense of traditional antihypertensive therapy. Hypertension 12:324-326

37. Wilkstrand J, Warnold I, Olsson G, Tuomilehto J, Elmfeldt D, Berglund G (1988) Primary prevention with metoprolol in patients with hypertension. Mortality results from the MAPHY Study. JAMA 259: 1976-1982

38. Mehta N, Modi N, Broughton Pipkin F, Baker PN, Symonds EM (1989) ACE inhibitors in pregnancy. Lancet II: 96-97 (letter)

39. Weidmann P, Beretta-Piccoli C, Keusch G, Glück Z, Mujagic M, Grimm M, Meier A, Ziegler WH (1979) Sodium-volume factor, cardiovascular reactivity and hypotensive mechanism of diuretic therapy in mild hypertension associated with diabetes mellitus. Am J Med 67: 779-784

40. Ray WA, Griffin MR, Downey W, Melton III LS (1989) Longterm use of thiazide diuretics and risk of hip fracture. Lancet I: $687-690$

41. Valvo E, Bedogna V, Casagrande $P$, Antiga L, Zamboni M, Bommartini F, Oldrizzi L, Rugiu C, Maschio G (1988) Captopril in patients with type 2 diabetes and renal insufficiency: systemic and renal hemodynamic alterations. Am J Med 85: 344-348

42. Packer M, Lee WH, Medina N, Yushak M, Kessler PD, Gottlieb SS (1987) Influence of diabetes mellitus on changes in left ventricular performance and renal function produced by converting enzyme inhibition in patients with severe chronic heart failure. Am J Med 82: 1119-1126

43. Webster J, Murchison LE, Robb OJ (1988) Angiotensin converting enzyme inhibitors may cause renal impairment in diabetes mellitus. Scott Med 33: 247-248

44. Sawicki PT, Kaiser S, Ehle B, Frenzel H, Kemmer F (1989) Autopsy study on renal artery stenosis in diabetes mellitus. Diabetes 38 [Suppl 2]: 129A

45. Day JL, Humphreys H, Alban-Davies H (1987) Problems of comprehensive shared diabetes care. Br Med J 294: 1590-1592

46. Billault B, Leblanc H, Passa Ph (1988) Care of arterial hypertension in 612 insulin-treated diabetic outpatients. Second International Symposium on Hypertension Associated with Diabetes Mellitus. Paris. Abstract Volume, pp 0-3

47. Parving HH, Hommel E, Mathiesen E, Skott $P$, Edsberg B, Bahnsen M, Lauritzen M, Hougaard P, Lauritzen E (1989) Prevalence of microalbuminuria, hypertension, retinopathy and neuropathy in patients with insulin dependent diabetes. Br Med J 296: $156-160$

\section{Dr. P.T.Sawicki}

Medizinische Klinik der Heinrich-Heine Universität

Abteilung für Stoffwechsel und Ernährung

Moorenstrasse 5

D-4000 Düsseldorf 1

FRG 